\title{
音響信号を利用したカーネル判別器による疲労紙幣検出
}

\section{一Divergence-based カーネルを用いた時変スペクトル判別—}

\author{
石垣 司*・樋 口知 之* \\ Detection of Worn-out Banknote by Using Acoustic Signals \\ - Time-varying Spectrum Classification by Divergence-based Kernel Machines- \\ Tsukasa ISHIGAKI* and Tomoyuki HigUCHI*
}

\begin{abstract}
In Japan, the quality of paper banknotes in circulation is maintained at a high level. The main reasons for this are as follows: (1) to facilitate the detection of counterfeit banknotes, and (2) to prevent paper jam problems in automated teller machines. Old, stained, or badly wrinkled banknotes frequently cause these problems. Such banknotes are removed from circulation and discarded by the Bank of Japan. In this paper, we introduce the time-varying spectrum classification method based on the SVM and RVM with the divergence-based kernel and apply this method to the detection of worn-out banknotes. The divergence gives a metric between two probability distributions, and the divergence-based kernel was proposed as a measure between two probability distributions in the kernel method. Here, two data sets are used for verification of classification performance, and the sound of flicking of banknotes is considered as the analyzed object. The obtained result shows a higher classification performance than some common methods.
\end{abstract}

Key Words: kernel classifier, divergence-based kernel, time-varying spectrum, worn-out banknote detection, spectrum classification

\section{1.はじめに}

現在, 日本国内において流通している紙幣はある一定以上 の高い品質が維持されている. その主な理由は二つある。一 つは偽札の発見を容易にするため, もう一つは ATM や自動 販売機などの自動紙幣取扱機の紙詰まりによる故障を防ぐた めである，流通により紙質が劣化した紙幣（以下, 疲労紙幣 と呼ぶ）はこのような問題を引き起こしやすい. そのため, 日本銀行では自動検出機を用いて回収した紙幣の中から疲労 紙幣を検出し，再び流通することがないように破棄している. また, 市販の現金計数装置においても，疲労紙幣を検出し，流 通から除外する装置が組み込まれているものがある.

疲労紙幣の自動検出機は光学的診断によるものと, 音響的 診断によるものに分けられる．現在，実用化されている自動 検出法は画像センサや赤外線センサなどを用いた光学的な診 断方法が主であり, 高い検出性能を示している ${ }^{1)}$. 光学的診 断では, 経験的に知られている疲労が起こりやすい部位を光

* 情報・システム研究機構統計数理研究所 東京都港区南麻布 4-6-7

* The Institute of Statistical Mathematics, Research Organization of Information and Systems, 4-6-7 Minami-Azabu, Minato-ku, Tokyo

(Received January 8, 2008)

(Revised April 11, 2008)
学的センサで走査することにより診断を行なう。そのため, 紙幣の厳密な位置決めが必要であり, そのための機構を付加 的に組み込む必要がある．また，日本国紙幣のみにおいて経 験的に知られている部分を診断の特徵量として使用している ため，他国の紙幣や他分野の紙質検査への直接的な応用は困 難である。一方，紙幣の擦れや弾き音による音響信号を用い て疲労紙幣の検出を行なう研究も存在する ${ }^{2) ~ 5)}$. この方法で は紙幣が計数装置に取り込まれる際に自然に発生する音を利 用できるため, 厳密な位置決めのための機構は必要ない。ま た，ある一部分を走査するのではなく，紙幣全体が発する音 響から紙質を診断するため, 他分野への発展的な応用も期待 できる．しかしながら，既存の音響的診断手法は光学的手法 に比べ, 検出性能が低い.

本論では音響信号を利用した高精度な疲労紙幣の検出方法 について述べる，紙幣の弾き音に注目し，そのスペクトル構 造を特徴量とすることで疲労紙幣の検出を行なう。しかしな がら，紙幣の疲労度合いがどのように音響信号の周波数スペ クトルに影響を与えるかは不明である，そのため，機械学習 によるアプローチを採用し，音響信号の時変スペクトル構造 をカーネル学習機械に学習させ, 疲労紙幣の検出を行なう.

カーネル学習判別機械は Support Vector Machine (SVM) 6),7)の成功により, 多様な分野において利用されるようになっ ている. しかしながら, 高い判別性能を得るためのカーネル 
関数の選択・設計法に一般的な指標はなく, 利用するカーネル 関数における判別性能は，与えられたデー夕の構造・分布に大 きく依存する．ただし，逆の観点から見ると，与えられたデー 夕に対して適切なカーネル関数を用いることで，一般に使用さ れているカーネル関数よりも,より判別能力の高いカーネル判 別器を構成することができる。そこで，われわれは二つの確率 密度間の類似度を測るカーネル関数である divergence-based カーネルに着目し，それを時変スペクトルの類似度を測る尺 度へと適用する。しかしながら, divergence-based カーネル は正定值性が満たされないものが多い.SVMでは正定值性を 満たさないカーネル関数はその構造から最適化計算の収束が 保証されない.そこで, 本論では非正定值なカーネル関数で も利用可能である Relevance Vector Machine (RVM) ${ }^{8), 9)}$ と SVM を採用し，二つのカーネル判別器により疲労紙幣検 出の検出精度を調べる。

\section{2. 音響信号の取得}

\section{1 実験に使用した紙幣}

本研究では，日本国紙幣千円札を実験対象として使用する. 痩労紙幣の定義は厳密ではなく，また，先行研究においても その定義は明確にされていない.そこで，本研究では通常の 紙幣（以下，流通可紙幣と呼ぶ）と疲労紙幣を以下のように 作成・定義し，音響信号の計測に用いる．流通している同程 度の使用感がある千円札 6 枚を用意し，そのうちの 3 枚を流 通可紙幣と定義した．そして，残りの紙幣を 1 枚ずつ片手の 手の平に乗せ，紙幣が手の中に収まるように 1 度だけ拳をに ぎる.その後，紙幣を取り出し，紙幣のしわを伸ばし整形し たものを疲労紙幣として定義する。この操作により人工的に 作成された 3 枚の疲労紙幣を以下の実験で使用する.

\section{2 音響信号データの計測方法}

本論では紙幣の弾き音に着目して検証を進める。ここでは, 2 つの方法で音響信号データの取得を行なった.一つ目の方 法（以下，実験 1 と称する）は, Fig. 1 に示すとおり，紙 幣を台から 3 分の 1 ほどはみ出すように固定し，はみ出して いる部分にプラスチックの棒を衝突させ，その音響を計測し た.ここでは 3 枚の流通可紙幣と 3 枚の疲労紙幣を用いて計 測を行ない，流通可紙幣 50 データ，疲労紙幣 50 デー夕を取 得した。

二つ目の方法 (以下, 実験 2 と称する) は, 10 人の男女に 1 枚の紙幣を自由にもたせ，それを指で弾く音響を計測した。 そのとき, 紙幣のもち方, 弾き方, 弾く強さは各個人に自由 に決めてもらい，また，それらをできるだけ変化させるよう に指示した。この実験を各人が流通可紙幣，疲労紙幣に対し それぞれ 10 回行ない，流通可紙幣 100 データ，疲労紙幣 100 データを取得した。

実験 1 , 実験 2 ともに紙幣から $10 \mathrm{~cm}$ の距離に設置され たマイクロフォンを使用し, サンプリング周波数 $10 \mathrm{kHz}$ 計測した. Fig. 2 (a) に実験 1 によって得られた音響信号を Fig. 2 (b) にその時変スペクトルを示す. 時変スペクトルを

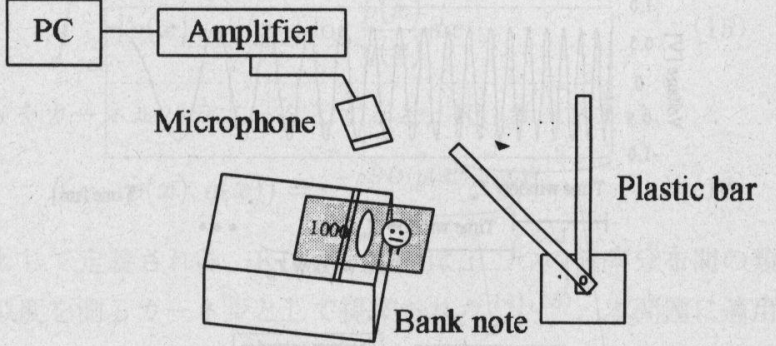

Fig. 1 System for measuring the sound of 'flicking' a fixed banknote in experiment 1
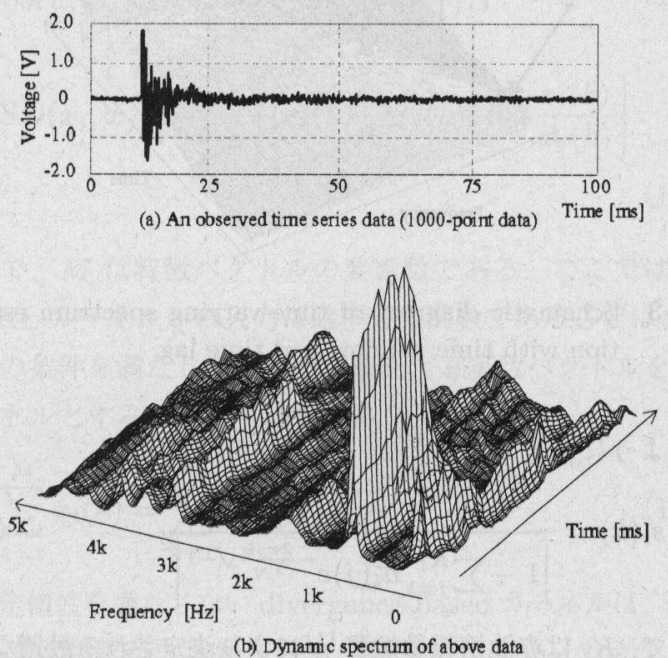

Fig. 2 Observed impact acoustic signal and estimated timevarying spectrum

計算する際に, すべての時刻 $t$ において瞬時スペクトルを計 算することは計算量の観点から実用的ではない. そこで, 本 論では Fig. 3 に示すように時間空 $T_{w}$ と時間空移動ラグ $L$ を 用い時変スペクトルの推定を行なう.

これらの音響信号取得方法は従来の研究に比べ Ad-hoc な ものである. よって,これらのデータにおいて高い検出性能が 得られた場合, 厳密に音響信号が計測できる従来の方法におい ても高い検出性能をもつことが期待できる.なお, Fig. 2 (b) は時間空 $T_{w}=100$, 時間空移動ラグ $L=10$ として計算した.

\section{3. 特徵量の抽出}

上記の方法により計測された音響信号 $i$ において, $0.1[\mathrm{~V}]$ を閾值としその閾值を超えたデー夕点からつぎの 1000 デー 夕点を取り出し, その時系列信号 $z_{i}=\left[z_{i}(1), \cdots, z_{i}(t), \cdots\right.$, $\left.z_{i}(1000)\right]^{T}$ を判別実験のためのデータとして用いる. その データを使用し音響信号 $i$ の特徴べクトル $\boldsymbol{x}_{i}$ を構成する. ここで, $T_{w}$ と $L$ は実験的に決定し, それぞれ $T_{w}=100$, $L=30$ とした。

ここでは，四つのスペクトルを特徴量として採用する。 (i) 時不変スペクトル $(\mathrm{SS}): \mathrm{AR}$ 法によりデータ $i$ の時不変スペ クトルを推定する．時不変スペクトルの周波数成分を $s_{i}(k)$, 与えられた時系列データの点数を $T_{N}$ とおくと, その值は以 


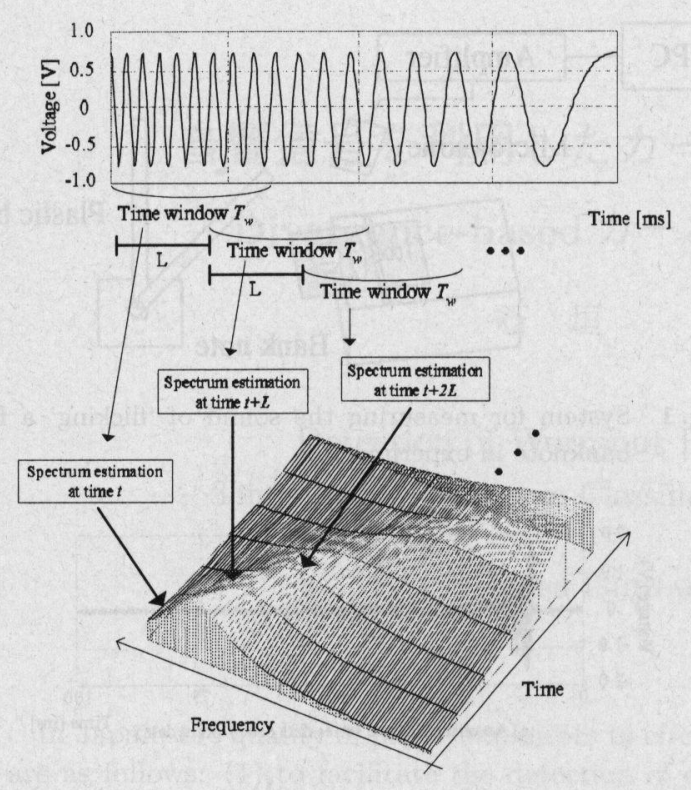

Fig. 3 Schematic diagram of time-varying spectrum estimation with time window and time lag

下のように推定できる ${ }^{10)}$.

$$
s_{i}(k)=\frac{\sigma_{i}^{2}}{\left|1-\sum_{j=1}^{K_{i}} a_{i}(j) e^{-\frac{2 \pi j k}{T_{N}} \sqrt{-1}}\right|^{2}} .
$$

ここで, $K_{i}$ は赤池情報量規準 ${ }^{11)}$ により決定される最適な $\mathrm{AR}$ 次数である. また, $m$ 次の AR 係数 $a_{i}(m)$ と $\sigma_{i}^{2}$ は $\boldsymbol{z}_{i}$ を用い Yule-Walker 法により決定した. また, 周波数成分は $100 \mathrm{~Hz}$ ごとに $0 \mathrm{~Hz}$ から $5 \mathrm{kHz}$ まで推定した.この $s_{i}(k)$ を用い, 以 下のように特徵べクトルを構成する。

$$
\boldsymbol{x}_{i}=\frac{1}{\sum_{k=1}^{N_{f}} s_{i}(k)}\left[s_{i}(1), \cdots, s_{i}\left(N_{f 1}\right)\right]^{T} .
$$

ここで $N_{f 1}=501$ である.

(ii) 時変ピリオドグラム $(\mathrm{TVP})$ : データ $i$ の時刻 $t$ における 正規化された時変ピリオドグラム $p_{i t}$ は DFTにより次式で 計算する.

$$
\begin{aligned}
& p_{i t}(k)=\left|\sum_{j=1}^{T_{w}} z_{i}(t+j) e^{-\frac{2 \pi k j}{T_{w}+1} \sqrt{-1}}\right|^{2} . \\
& \overline{\boldsymbol{p}}_{i t}=\frac{1}{\sum_{k=1}^{N_{f}} p_{i t}(k)}\left[p_{i t}(1), \cdots, p_{i t}\left(N_{f 2}\right)\right]^{T} .
\end{aligned}
$$

ここで $N_{f 2}=51$ である. 以下, (iii), (iv) の各時刻に推定 される周波数スペクトル成分数はこの值を用いる. 時間空移 動ラグを考慮し, 特徴ベクトルを構成する。

$$
\boldsymbol{x}_{i}=\left[\overline{\boldsymbol{p}}_{i 1}^{T}, \overline{\boldsymbol{p}}_{i L}^{T}, \overline{\boldsymbol{p}}_{i(2 L)}^{T}, \cdots, \overline{\boldsymbol{p}}_{i\left(N_{p} L\right)}^{T}\right]^{T},
$$

ここで, $N_{p}$ は計算されたピリオドグラム $\bar{p}_{i t}$ の数である. (iii)AR 法により推定された時変スペクトル (TVS) : 各時刻 で AR 法により推定されたスペクトルを用いて，時変ピリオ ドグラムと同様に特徴ベクトルを構成する。 (iv) 平滑化処理を行なった AR 係数により構成された時変ス ペクトル (STVS)：上記 (iii) で推定された AR 係数に対して 時間方向に 1 次のトレンドモデルを仮定し, Kalman フィル 夕，Kalman スムーザにより平滑化処理を施した時変スペク トルにより特徴量を構成する ${ }^{10)}$.

\section{4. カーネル判別器}

\section{1 カーネル法}

ここでは, カーネル法 ${ }^{12)}{ }^{13)}$ を用いた判別学習機械の概略 について述べる.

今, $N$ 個の入出力のペア $\left(\boldsymbol{x}_{i}, y_{i}\right) \in X \times Y, Y=\{-1,1\}$ $(i=1, \cdots, N)$ と, その入出力ペア (学習データ) から構成 される線形判別器を考える.このとき判別超平面は重み係数 を $\boldsymbol{w}$, 定数を $w_{0},<·>$ を内積とすると，

$$
f(\boldsymbol{x})=\left\langle\boldsymbol{w} \cdot \boldsymbol{x}>+w_{0}\right.
$$

で表わすことができる.

ここで, 上の線形判別器の非線形判別器への拡張のため に入力ベクトル空間 $X$ から特徵空間 $Z$ への非線形写像 $\Phi: X \rightarrow Z$ を導入し, 入力 $x_{i}$ と $x_{j}$ の類似度をその空 間内で $<\Phi\left(\boldsymbol{x}_{i}\right) \cdot \Phi\left(\boldsymbol{x}_{j}\right)>_{z}$ として定義できる.この内積を 入力空間の関数として

$$
K\left(\boldsymbol{x}_{i}, \boldsymbol{x}_{j}\right)=<\Phi\left(\boldsymbol{x}_{i}\right) \cdot \Phi\left(\boldsymbol{x}_{j}\right)>z
$$

と表わすことができ, その関数 $K\left(\boldsymbol{x}_{i}, \boldsymbol{x}_{j}\right)$ をカーネルと呼ぶ. ここで, カーネル関数として, 陽に高次元特徴空間での内積 の計算をする必要がない関数を選ぶことで, 類似度の計算量 を大幅に削減できる.

つまり，カーネル関数を導入することはその非線形関数 $\Phi$ により射影された高次元空間内で線形判別超平面を構築する ことと等しい. それゆえに，判別器の判別能力はカーネル関 数の選択に大きく依存する。

\subsection{Support Vector Machine}

SVM は 2 值クラス判別のための線形判別学習機である. 一般に与えられたデータセットが線形分離可能であればその 判別超平面は無限個存在するが, SVM はマージン (判別超 平面に一番近いトレーニングデータと超平面との距離）が最 大になる超平面を一意に決定できる，それは，(6) 式のその 双対空間での最適化問題として次式で定式化できる.

$$
\begin{array}{ll}
\text { maximize } & \sum_{i=1}^{N} \alpha_{i}-\frac{1}{2} \sum_{i, j=1}^{N} y_{i} y_{j} \alpha_{i} \alpha_{j}\left\langle x_{i} \cdot x_{j}\right\rangle \\
\text { subject to } & \sum_{i=1}^{N} y_{i} \alpha_{i}=0,0 \leq \alpha_{i} \leq C
\end{array}
$$

ただし,$a_{i}$ はラグランジュ乗数, $C$ は正則化パラメータとす る. $C$ は判別超平面の複雑さとテストデータにおける SVM の誤差のトレードオフを制御するパラメータである。 また， 上式を 


$$
<\boldsymbol{x}_{i} \cdot \boldsymbol{x}_{j}>\rightarrow K\left(\boldsymbol{x}_{i}, \boldsymbol{x}_{j}\right) .
$$

と変更することでSVM は非線形判別器となる. そして, そ の判別超平面は以下のように構成される.

$$
f(\boldsymbol{x})=\sum_{i=1}^{N} \alpha_{i} K\left(\boldsymbol{x}, \boldsymbol{x}_{i}\right)+\alpha_{0}
$$

\section{3 Relevance Vector Machine}

RVM はカーネル法を応用した Bayesian 判別器として提案 された，RVM はSVM と比較して以下の特徴がある. (1) 確 率を出力とする。(2) 判別平面を構成するために用いるデー タがSVM よりも少なくなる傾向にある (3) 正則化パラメー 夕に関して経験 Bayes 法により決定できる. (4) カーネル関 数が正定值性を満たす必要はない。ここでは (4)の性質が, 正定值性を満たす保障のない divergence-based カーネルの適 用に対して都合が良い。

重みべクトル $\boldsymbol{w}$ と入力 $\boldsymbol{x}$ が与えられたとき，ある基底関 数 $\phi(\boldsymbol{x})$ に対する線形結合 $\boldsymbol{w}^{T} \phi(\boldsymbol{x})$ のロジスティック関数 $\sigma(a)=\{1+\exp (-a)\}^{-1}$ による出力

$$
f(\boldsymbol{x}, \boldsymbol{w})=\sigma\left(\boldsymbol{w}^{T} \phi(\boldsymbol{x})\right)
$$

を考える．また，入力データが与えられたときの Bernoulli 分布 $p(y \mid \boldsymbol{x})$ を考えると, その尤度関数は次式のようになる.

$$
p(y \mid \boldsymbol{w})=\prod_{i=1}^{N} \sigma\left\{f\left(\boldsymbol{x}_{\boldsymbol{i}}, \boldsymbol{w}\right)\right\}^{y_{i}}\left[1-\sigma\left\{f\left(\boldsymbol{x}_{\boldsymbol{i}}, \boldsymbol{w}\right)\right\}\right]^{1-y_{i}}
$$

ここで, $\boldsymbol{w}$ の事前分布を

$$
p(\boldsymbol{w} \mid \boldsymbol{\beta})=\prod_{i=0}^{N} N\left(w_{i} \mid 0, \beta_{i}^{-1}\right)
$$

とし, (12) 式の尤度関数を最大化するような重みベクトル $\boldsymbol{w}$ とハイパーパラメータ $\boldsymbol{\beta}$ 推定することにより RVM が構成 される．ただし，ここで， $N(w \mid 0, \beta)$ は $w$ に対する平均 0 , 分散 $\beta$ の Gauss 分布とする。ここでも SVM と同様に，そ の出力は (10) 式を含む形式で書き表わすことができる.

\subsection{Divergence-based カーネル}

Divergence は二つの確率分布間の近さを測る指標として使 用され, 確率変数 $\boldsymbol{x}$ と二つの確率分布 $p(\boldsymbol{x}), q(\boldsymbol{x})$ の近さを定 義する.この量は, 二つの分布が同一であるときに 0 の值を とり，值が大きくなるほど二つの分布は遠くなると考えるこ とができる.ここでは代表的な divergence である KullbackLeibler (KL) divergence

$$
D(p(\boldsymbol{x}), q(\boldsymbol{x}))=\int_{-\infty}^{\infty} p(\boldsymbol{x}) \log \frac{p(\boldsymbol{x})}{q(\boldsymbol{x})} d \boldsymbol{x}
$$

を例にとり divergence-based カーネルの適用を検討する.

ここで, カーネル関数は対称関数である必要があるため, 以下の対称化 KL divergence $S D$ を考える.

$$
S D_{K L}(p(\boldsymbol{x}), q(\boldsymbol{x}))=
$$

$$
\int_{-\infty}^{\infty}\{p(\boldsymbol{x})-q(\boldsymbol{x})\} \log \frac{p(\boldsymbol{x})}{q(\boldsymbol{x})} d \boldsymbol{x}
$$

$\rho$ をカーネルパラメータとすると, KL カーネルは

$$
K_{K L}(p(\boldsymbol{x}), q(\boldsymbol{x}))=e^{-\rho S D(p(\boldsymbol{x}), q(\boldsymbol{x}))}
$$

として定義される．KL カーネルは，二つの確率分布間の類 似度を測るカーネルとして提案された ${ }^{14), 15)}$. 本問題に適用 するため, 離散化した KL カーネルを以下のように再定義す $ろ^{16)}$.

$$
\begin{aligned}
& K_{K L}\left(\boldsymbol{x}_{i}, \boldsymbol{x}_{j}\right)=\exp \left\{-\rho S D\left(\boldsymbol{x}_{i}, \boldsymbol{x}_{j}\right)\right\} \\
& S D\left(\boldsymbol{x}_{i}, \boldsymbol{x}_{j}\right)=\sum_{k=1}^{M}\left[\left\{x_{i}(k)-x_{j}(k)\right\} \log \frac{x_{i}(k)}{x_{j}(k)}\right]
\end{aligned}
$$

ここで， $M$ は特徵べクトルの要素数である．ここではもは や, KL カーネルへの入力は確率分布関数である必要はなく, 次式の条件を満たし各要素が正值をとる実数べクトルを入力 ベクトルとすることが可能である.

$$
\sum_{k=1}^{M} x_{i}(k)=\sum_{k=1}^{M} x_{j}(k)
$$

正定值性を満たさない divergence-based カーネルは, SVM の最適化問題が大域解に収束する保障はない. しかしなが ら，14)，17)，18)などの確率分布を想定したデータに対して行な われた判別実験では KL カーネルは良好な結果を示している. また，KL カーネルは入カベクトルの要素に非正值が存在す ると計算不可能になるが, ここでは正規化したスペクトルを 入力としているためカーネル関数の計算が可能である.

\section{5. 判別 実 験}

\section{1 実験と結果}

流通可紙幣, 疲労紙幣のデータセットからおのおの半数を ランダムに学習データとして取り出し, 残りの半数のデータ を判別させた。つまり, 実験 1 では流通可紙幣, 疲労紙幣各 25 データを判別器構成のための学習データとし, 残りの 50 データを判別実験に使用した. 同様に実験 2 では流通可紙幣, 疲労紙幣各 50 データを判別器構成のための学習データとし, 残りの 100 デー夕を判別実験に使用した. SVM と RVM を 用いて，この実験をそれぞれの特徵べクトルとカーネル関数 に関して 100 回繰り返した平均值を判別性能として評価する.

また, 本実験では 13 種類のカーネル関数を使用した。そ れらは 1 次から 5 次の多項式, Gaussian, Sigmoid, Laplacian, Sub-linear, $\chi^{2}$, Hellinger, Bhattacharyya, KullbackLeibler カーネルである. それぞれのカーネル関数は付録に 記載する. 多項式, Gaussian, Sigmoid カーネルは一般的に よく用いられるカーネルであり, Laplacian, Sub-linear, $\chi^{2}$ カーネルはヒストグラム判別によく用いられるカーネルであ る. Hellinger, Bhattacharyya, Kullback-Leibler カーネル 
Table 1 Accuracy percentages and standard deviations of fixed banknote data set by combinations of kernel functions and features by SVM and RVM

\begin{tabular}{|c||c|c|c|c||c|c|c|c|}
\hline \multicolumn{1}{|c||}{} & \multicolumn{4}{c||}{ SVM } & \multicolumn{4}{c|}{ RVM } \\
\hline \hline \multicolumn{1}{|c||}{} & SS & TVP & TVS & STVS & SS & TVP & TVS & STVS \\
\hline 1st-order polynomial & $85.3( \pm 5.4)$ & $87.3( \pm 4.6)$ & $90.1( \pm 3.9)$ & $90.4( \pm 3.8)$ & $83.5( \pm 5.0)$ & $85.4( \pm 4.7)$ & $87.5( \pm 4.2)$ & $87.5( \pm 4.6)$ \\
\hline 2nd-order polynomial & $85.2( \pm 5.4)$ & $87.6( \pm 3.8)$ & $92.2( \pm 3.5)$ & $91.4( \pm 3.4)$ & $83.7( \pm 5.0)$ & $86.6( \pm 4.8)$ & $88.1( \pm 4.9)$ & $88.0( \pm 4.6)$ \\
\hline 3rd-order polynomial & $86.1( \pm 5.4)$ & $87.1( \pm 3.9)$ & $92.1( \pm 3.2)$ & $91.5( \pm 3.4)$ & $84.0( \pm 4.4)$ & $86.3( \pm 4.8)$ & $88.4( \pm 4.5)$ & $88.4( \pm 4.5)$ \\
\hline 4th-order polynomial & $85.7( \pm 5.2)$ & $87.4( \pm 4.4)$ & $92.3( \pm 3.4)$ & $93.2( \pm 3.4)$ & $84.4( \pm 4.8)$ & $85.5( \pm 4.5)$ & $88.5( \pm 4.7)$ & $88.5( \pm 4.3)$ \\
\hline 5th-order polynomial & $86.7( \pm 4.9)$ & $87.3( \pm 4.2)$ & $92.7( \pm 3.2)$ & $92.4( \pm 3.2)$ & $84.0( \pm 4.9)$ & $86.0( \pm 4.4)$ & $88.0( \pm 4.6)$ & $88.3( \pm 4.7)$ \\
\hline Sigmoid & $88.5( \pm 3.7)$ & $84.0( \pm 4.5)$ & $90.0( \pm 4.3)$ & $90.1( \pm 3.9)$ & $81.3( \pm 5.5)$ & $82.3( \pm 4.6)$ & $85.9( \pm 4.5)$ & $84.2( \pm 4.7)$ \\
\hline Gaussian & $90.4( \pm 3.3)$ & $91.9( \pm 3.3)$ & $93.4( \pm 3.6)$ & $92.7( \pm 3.2)$ & $87.7( \pm 4.3)$ & $88.5( \pm 4.1)$ & $88.9( \pm 3.2)$ & $89.5( \pm 3.4)$ \\
\hline Laplacian & $90.9( \pm 3.1)$ & $95.8( \pm 2.5)$ & $98.1( \pm 2.3)$ & $98.2( \pm 1.9)$ & $87.9( \pm 3.5)$ & $88.5( \pm 4.1)$ & $95.5( \pm 2.8)$ & $95.7( \pm 3.0)$ \\
\hline Sublinear & $90.4( \pm 3.4)$ & $96.9( \pm 2.4)$ & $97.7( \pm 3.5)$ & $97.4( \pm 2.9)$ & $88.4( \pm 3.4)$ & $89.5( \pm 4.0)$ & $96.6( \pm 3.1)$ & $96.4( \pm 2.9)$ \\
\hline$\chi^{2}$ & $91.2( \pm 3.3)$ & $97.1( \pm 2.1)$ & $98.6( \pm 2.1)$ & $99.0( \pm 2.1)$ & $90.1( \pm 3.5)$ & $89.2( \pm 3.8)$ & $95.6( \pm 2.6)$ & $95.7 .( \pm 2.7)$ \\
\hline Hellinger & $91.6( \pm 3.5)$ & $97.4( \pm 2.0)$ & $99.1( \pm 1.8)$ & $99.3( \pm 2.0)$ & $91.0( \pm 2.8)$ & $92.2( \pm 3.8)$ & $96.6( \pm 2.2)$ & $96.0( \pm 2.4)$ \\
\hline Bhattacharyya & $91.7( \pm 2.9)$ & $98.0( \pm 2.6)$ & $\mathbf{9 9 . 4}( \pm 1.3)$ & $\mathbf{9 9 . 4}( \pm 1.4)$ & $91.0( \pm 2.3)$ & $92.9( \pm 3.6)$ & $95.7( \pm 2.1)$ & $95.4( \pm 2.4)$ \\
\hline Kullback-Leibler & $92.4( \pm 3.6)$ & $97.7( \pm 2.0)$ & $\mathbf{9 9 . 4}( \pm 1.3)$ & $\mathbf{9 9 . 4}( \pm 1.3)$ & $92.0( \pm 2.3)$ & $91.5( \pm 3.4)$ & $96.0( \pm 2.0)$ & $96.1( \pm 2.1)$ \\
\hline
\end{tabular}

Table 2 Accuracy percentages and standard deviations of freely flicked data set by combinations of kernel functions and features by SVM and RVM

\begin{tabular}{|c||c|c|c|c||c|c|c|c|}
\hline \multicolumn{1}{|c||}{} & \multicolumn{4}{c||}{} & \multicolumn{3}{c|}{ RVM } \\
\hline \hline \multicolumn{1}{|c||}{} & SS & TVP & TVS & STVS & SS & TVP & TVS & STVS \\
\hline 1st-order polynomial & $82.3( \pm 3.4)$ & $83.5( \pm 3.4)$ & $84.5( \pm 3.5)$ & $85.5( \pm 3.2)$ & $81.7( \pm 3.5)$ & $82.7( \pm 3.5)$ & $84.7( \pm 3.8)$ & $85.0( \pm 3.5)$ \\
\hline 2nd-order polynomial & $82.2( \pm 3.6)$ & $84.4( \pm 3.5)$ & $86.2( \pm 3.4)$ & $85.8( \pm 3.2)$ & $81.4( \pm 3.5)$ & $82.4( \pm 4.0)$ & $84.6( \pm 3.6)$ & $84.8( \pm 3.7)$ \\
\hline 3rd-order polynomial & $82.6( \pm 3.1)$ & $83.6( \pm 3.3)$ & $85.5( \pm 3.3)$ & $85.6( \pm 3.2)$ & $82.0( \pm 3.4)$ & $82.8( \pm 3.7)$ & $85.0( \pm 3.4)$ & $85.2( \pm 3.7)$ \\
\hline 4th-order polynomial & $82.3( \pm 3.3)$ & $83.3( \pm 3.2)$ & $85.6( \pm 3.0)$ & $86.1( \pm 3.1)$ & $81.9( \pm 3.3)$ & $82.5( \pm 4.0)$ & $85.0( \pm 3.6)$ & $84.9( \pm 3.4)$ \\
\hline 5th-order polynomial & $83.4( \pm 3.3)$ & $83.4( \pm 3.1)$ & $86.0( \pm 3.1)$ & $85.4( \pm 3.0)$ & $81.5( \pm 3.3)$ & $82.6( \pm 3.6)$ & $84.9( \pm 4.0)$ & $84.6( \pm 3.8)$ \\
\hline Sigmoid & $83.4( \pm 3.7)$ & $84.6( \pm 3.6)$ & $82.7( \pm 3.9)$ & $81.0( \pm 4.0)$ & $80.9( \pm 4.0)$ & $79.5( \pm 3.8)$ & $82.1( \pm 3.7)$ & $83.1( \pm 3.8)$ \\
\hline Gaussian & $85.4( \pm 4.0)$ & $83.4( \pm 3.3)$ & $87.6( \pm 3.1)$ & $88.5( \pm 3.3)$ & $84.0( \pm 3.7)$ & $83.4( \pm 3.5)$ & $86.6( \pm 3.2)$ & $86.6( \pm 3.4)$ \\
\hline Laplacian & $86.5( \pm 3.0)$ & $84.9( \pm 3.1)$ & $87.8( \pm 3.6)$ & $87.9( \pm 3.8)$ & $83.3( \pm 3.5)$ & $82.8( \pm 3.5)$ & $85.6( \pm 3.4)$ & $86.0( \pm 3.4)$ \\
\hline Sublinear & $86.4( \pm 3.0)$ & $84.4( \pm 3.0)$ & $89.6( \pm 3.4)$ & $90.2( \pm 3.5)$ & $83.2( \pm 3.5)$ & $83.3( \pm 3.8)$ & $88.9( \pm 3.2)$ & $87.9( \pm 3.5)$ \\
\hline$\chi^{2}$ & $87.0( \pm 2.8)$ & $87.2( \pm 3.5)$ & $90.9( \pm 2.7)$ & $90.3( \pm 3.1)$ & $82.2( \pm 3.4)$ & $82.5( \pm 3.6)$ & $88.1( \pm 2.7)$ & $88.0( \pm 2.9)$ \\
\hline Hellinger & $86.9( \pm 2.8)$ & $89.0( \pm 2.9)$ & $91.6( \pm 2.4)$ & $92.0( \pm 2.2)$ & $85.2( \pm 3.3)$ & $84.7( \pm 3.2)$ & $90.0( \pm 2.5)$ & $88.7( \pm 2.7)$ \\
\hline Bhattacharyya & $87.1( \pm 2.6)$ & $89.2( \pm 3.5)$ & $91.8( \pm 2.5)$ & $92.0( \pm 2.3)$ & $85.5( \pm 3.2)$ & $87.5( \pm 2.9)$ & $89.9( \pm 2.2)$ & $90.2( \pm 2.1)$ \\
\hline Kullback-Leibler & $87.7( \pm 2.7)$ & $89.8( \pm 3.2)$ & $92.0( \pm 2.3)$ & $\mathbf{9 2 . 1}( \pm 2.0)$ & $86.5( \pm 2.9)$ & $87.0( \pm 3.0)$ & $90.1( \pm 2.3)$ & $90.0( \pm 2.4)$ \\
\hline
\end{tabular}

は divergence-based カーネルである。

実験 1 の結果を Table 1 に実験 2 の結果を Table 2 に示 す. 值は 100 回の試行の平均正判別率 [\%] であり，括弧内の 数值はその標準偏差である.SVMにおいてカーネルパラメー 夕 $\rho$ と正則化パラメータ $C$ はグリッドサーチによる Crossvalidation により最適な值に決定した。 また，RVMにおい て各 RVM 内のパラメータは Laplace 近似 ${ }^{9}$ による尤度を最 大化することにより求め，カーネルパラメータ $\rho$ は Crossvalidation によりその值を決定した.

\section{2 考察}

カーネル関数の選択に関して，実験 1 において Hellinger カーネル, Bhattacharyya カーネルと KL カーネルが平均 正判別率 $99 \%$ 以上という高い結果を示している．また，実験 2 においても同様のカーネル関数の使用が高い判別率を示し ている。これらの結果は, 通常使用される多項式カーネルや Gaussian カーネルの判別率と比べ，大きく上回っている．ま た，これらの結果は従来の研究の結果と比べても同様である.

特徵ベクトルに関して，時変スペクトル（TVSと STVS） が全体的に高い判別率を示している．両特徵ベクトルの結果 はほほ同等であり，時間方向への平滑化は本実験に対して影
響を与えていないと考えられる，しかしながら，時変ピリオ ドグラムは全体的に判別結果が劣っている。これにより，紙 幣音響信号の判別のためには，ある程度の適切な周波数成分 に対する平滑化処理が必要であることがわかる.

カーネル判別器の判別性能に関しては RVM よりも SVM のほうが平均的に数パーセント勝っている. また, SVM の最 適化計算において，本実験では一度も不都合は生じなかった。

\section{6. むす び}

本論では, 音響信号を利用した疲労紙幣の検出と divergencebased カーネルを応用した検出の高精度化について述べた. 本論の手法を用いることで，マイクロフォンと演算処理部に よる簡易な疲労紙幣検出装置の開発や, 他分野の紙質診断の ような発展的応用が期待できる. 実装置の音による判別実験, 紙幣の疲労度合いの判別については今後の課題である.

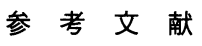

1）上杉文昭：污損券抽出装置およびそれを用いた現金取扱装置, 日本特許, P2003-242549A (2003)

2）寺西, 大松：音響信号を用いた紙幣の新旧判別, 統計数理研究 所共同研究リポート 106，65/70 (1998) 
3）寺西, 大松 : 三種の音響信号を用いた紙幣の新旧識別, 統計数 理研究所共同研究リポート 150, 39/45 (2002)

4) M. Teranishi, T. Matsui, S. Omatsu and T. Kosaka: Neuro-classification of fatigued bill based on tensional acoustic signal, the Proceedings of IEEE Mid-Summer Workshop on Soft Computing in Industrial Applications, $173 / 177$ (2005)

5）上原, 姜, 宮城：紙幣音響データの独立成分分析による正損判 別，電子情報通信学会技術研究報告，107-384，71/75 (2007)

6) N. Cristianini and J.S. Taylor: An Introduction to Support Vector Machines and Other Kernel-based Learning Methods, Cambridge University Press (2000)

7) V.N. Vapnik: Statistical learning theory, Wiley (1998)

8) M.E. Tipping: Sparse Bayesian Learning and the Relevance Vector Machine, Journl of Machine Learning Research, 1, 211/244 (2001)

9) C.M. Bishop: Pattern Recognition and Machine Learning, Springer (2006)

10）北川源四郎：時系列解析入門，岩波書店 (2005)

11) H. Akaike: A new look at the statistical model identification, IEEE Transaction on Automatic Control, 19-6, $716 / 723(1974)$

12) K-R. Müller, S. Kika, G. Ratsch, K. Tsuda and B. Schölkopf: An introduction to kernel-based learning algorithms, IEEE Transaction on Neural Networks, 12-2, $181 / 202(2001)$

13) J.S. Taylor and N. Cristianini: Kernel Methods for Pattern Analysis, Cambridge University Press (2004)

14) P.J. Moreno, P.P. Ho and N. Vasconcelos: A KullbackLeibler divergence based kernel for SVM classification in multimedia applications, The Proceedings of Neural Information Processing Systems (2003)

15) N. Vasconcelos, P. Ho and P. Moreno: The KullbackLeibler kernel as a framework for discriminant and localized representations for visual recognition, The Proceedings of 9th European Conference on Computer Vision, $430 / 441$ (2004)

16) T. Ishigaki, T. Higuchi and K. Watanabe: Spectrum classification for early fault diagnosis of LP gas pressure regulator based on Kullback-Leibler kernel, The Proceedings of IEEE Machine Leaning for Signal Processing, 453/458 (2006)

17) A.B. Chan and N. Vasconcelos: Probabilistic kernels for the classification of auto-regressive visual processes, The Proceedings of IEEE Computer Society Conference on Computer Vision and Pattern Recognition, 846/851 (2005)

18) S.K. Zhou and R. Chellappa: From sample similarity to ensemble similarity: probabilistic distance measures in reproducing kernel Hilbert space, IEEE Transaction on Pattern Analysis and Machine Intelligence, 28, 917/929 (2006)

\section{《付 録》}

\section{A. カーネル関数}

$d$ 次の多項式カーネル

$$
K_{P d}\left(\boldsymbol{x}_{i}, \boldsymbol{x}_{j}\right)=\left(\rho \boldsymbol{x}_{i}^{T} \cdot \boldsymbol{x}_{j}+b\right)^{d}
$$

Sigmoid カーネル

$$
K_{S i g}\left(\boldsymbol{x}_{i}, \boldsymbol{x}_{j}\right)=\tanh \left(\rho \boldsymbol{x}_{i}^{T} \cdot \boldsymbol{x}_{j}+b\right)
$$

$$
K_{G a}\left(\boldsymbol{x}_{i}, \boldsymbol{x}_{j}\right)=\exp \left[-\rho \sum_{k=1}^{M}\left\{\boldsymbol{x}_{i}(k)-\boldsymbol{x}_{j}(k)\right\}^{2}\right](\text { A. 3 })
$$

Laplacian カーネル

$$
K_{L a}\left(\boldsymbol{x}_{i}, \boldsymbol{x}_{j}\right)=\exp \left\{-\rho \sum_{k=1}^{M}\left|\boldsymbol{x}_{i}(k)-\boldsymbol{x}_{j}(k)\right|\right\}(\text { A. 4) }
$$

Sub-linear カーネル

$$
K_{S u b}\left(\boldsymbol{x}_{i}, \boldsymbol{x}_{j}\right)=\exp \left\{-\rho \sum_{k=1}^{M} \sqrt{\left|\boldsymbol{x}_{i}(k)-\boldsymbol{x}_{j}(k)\right|}\right\}
$$

$$
\begin{aligned}
& \chi^{2} \text { カーネル } \\
& K_{\chi^{2}}\left(\boldsymbol{x}_{i}, \boldsymbol{x}_{j}\right)=\exp \left[-\rho \sum_{k=1}^{M} \frac{\left\{\boldsymbol{x}_{i}(k)-\boldsymbol{x}_{j}(k)\right\}^{2}}{\boldsymbol{x}_{i}(k)+\boldsymbol{x}_{j}(k)}\right]
\end{aligned}
$$

Hellinger カーネル

$$
K_{H e}\left(\boldsymbol{x}_{i}, \boldsymbol{x}_{j}\right)=\exp \left[-\rho \sum_{k=1}^{M}\left\{\sqrt{\boldsymbol{x}_{i}(k)}-\sqrt{\boldsymbol{x}_{j}(k)}\right\}^{2}\right]
$$

Bhattacharyya カーネル

$$
K_{B h a}\left(\boldsymbol{x}_{i}, \boldsymbol{x}_{j}\right)=\exp \left\{\rho \log \sum_{k=1}^{M} \sqrt{\boldsymbol{x}_{i}(k) \boldsymbol{x}_{j}(k)}\right\}
$$

\section{[著 者 紹 介]}

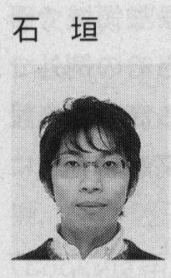

司（正会員）

2007 年総合研究大学院大学複合科学研究科統計 科学専攻博士課程修了. 現在, 科学技術振興機構 戦略的創造研究推進事業博士研究員, 兼, 情報・シ ステム研究機構統計数理研究所予測発見戦略研究 センター外来研究員. IEEE, 電子情報通信学会, 各会員. 博士 (学術).

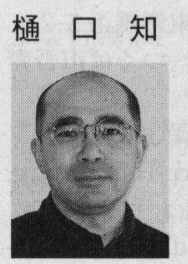

1989 年東京大学理学系研究科地球物理学専攻 博士課程修了. 現在, 情報・システム研究機構統 計数理研究所教授 (副所長). 専門は時系列モデル を中心としたベイジアンモデリング．日本統計学 会, 日本マーケティング・サイエンス学会, 地球 電磁気 - 地球惑星圈学会, International Statistical Institute, American Statistical Association, American Geophysical Union 各会員. 理学博士. 